\title{
CARIES PREVALENCE AMONG SCHOOLCHILDREN IN URBAN AND RURAL CROATIA
}

\author{
Stjepanka Lešić ${ }^{1}$, Walter Dukić ${ }^{2}$ Zdenka Šapro Kriste ${ }^{3}$, Vesna Tomičić ${ }^{4}$, Snježana Kadić ${ }^{5}$ \\ 1 Private Dental Practice Stjepanka Lešić, Štitar, Croatia \\ ${ }^{2} S$ chool of Dental Medicine, University of Zagreb, Zagreb, Croatia \\ ${ }^{3}$ Private Dental Practice Zdenka Šapro Kriste, Slano-Orašac, Croatia \\ 4Private Dental Practice Vesna Tomičić, Dubrovnik, Croatia \\ ${ }^{5}$ Dental Polyclinic Zagreb, Zagreb, Croatia
}

\begin{abstract}
SUMMARY
Objective: The aim of the study was to evaluate caries prevalence in a sample of schoolchildren aged 6 to 16 years from rural and urban areas in Croatia.

Methods: Using standardized World Health Organisation (WHO) criteria, the oral health status of 1,589 children (265 from rural and 1,324 from urban areas) was assessed by recording the following indices: DMFT (decayed, missing, filled permanent teeth), deft (decayed, extracted, filled primary teeth), DMFS (decayed, missing, filled surfaces - permanent teeth), defs (decayed, extracted, filled surfaces - primary teeth) and SiC (Significant Caries Index). Rural areas were Štitar and Babina Greda municipalities in Slavonia and urban areas were the cities of Županja (Slavonia), Zagreb and Dubrovnik.

Results: Half of the examined children (50.0\%) had caries (D component in DMFT), with $46.0 \%$ of these being from urban and $70.2 \%$ from rural areas. The median DMFT among children was 2, 4 (rural) and 2 (urban) ( $p<0.001$ ). Among 12-year-olds, the median DMFT was 4 (rural) and 3 (urban), and mean DMFT was 3.4. The median DMFS for rural area was 5 and for urban area 3 ( $p<0.001)$. The median deft was 1.00 for rural and 1.00 for urban, while the highest value was found among 6 -year-olds at 9 in rural and 7 in urban areas. The median SiC was 4, 4 (urban) and 5 (rural).

Conclusion: Schoolchildren from urban and rural areas in Croatia differ significantly in caries prevalence. They fall into the medium DMFT classification group according to the WHO, which indicates the need for a comprehensive oral health preservation programme.
\end{abstract}

Key words: epidemiology, dental caries, preventive dentistry, cross-sectional studies, paediatric dentistry, DMF index

Address for correspondence: W. Dukić, School of Dental Medicine, University of Zagreb, Gunduliceva 5, Zagreb, Croatia. E-mail: dukic@sfzg.hr https://doi.org/10.21101/cejph.a5314

\section{INTRODUCTION}

Oral health is an important and often overlooked component of general health and well-being. Oral health is defined by the World Health Organization (WHO) as: "Pain-free, healthy and functionally capable teeth and all parts of the oral cavity involved in chewing, as well as preserved aesthetics and phonation" (1). Caries of hard dental tissue is a disease caused by both infectious and nutritional factors, whose interactions are supported by environmental conditions. Colonization of cariogenic microorganisms from the genera Streptococcus, Lactobacillus and Bifidobacterium, presence of dentobacterial plaque on teeth surfaces, decreased salivary flow with low $\mathrm{pH}$, dietary habits based on consuming refined carbohydrates and irregular and inadequate oral hygiene, ultimately lead to demineralization of hard dental tissues (2-8).

Since 1938 the World Health Organisation has introduced - D (decay), M (missing), F (filling), T (tooth): DMFT/DMFS indices for permanent and deft/defs indices for primary teeth and surfaces in order to facilitate the tracking of caries epidemiology and in addition to assess the need to treat caries (9). In order to direct the necessary care to those individuals with the high indices, in 2000 the WHO introduces the $\mathrm{SiC}$ index, which highlights one third of the examinees with the highest DMFT index (10). Caries prevalence is the most important epidemiological method by which the insight into the oral health of the examined population can be gained (11). While there is a notable decrease in the developed countries of the Western and Northern Europe, in the countries of Eastern and Middle Europe there is still a considerable public health problem $(12,13)$. Reorganisation of the dental health care, the removal of specialized paediatric ambulances, as well as the absence of preventive procedures and the oral health promotion throughout a number of years are the reasons why Croatia is classified as a country with a high DMFT index. The WHO does not have unified data about the DMFT index in Croatia, it rather has the DMFT index data which are published in scientific articles (14). Good oral hygiene, healthy eating habits and regular systematic examinations are the most effective measures for preventing dental caries and periodontal disease. Brushing teeth at least twice daily with tooth brush and fluoride toothpaste presumes good oral hygiene (15). Worldwide, elementary schoolchildren typically brush their teeth once daily, and socioeconomic status affects oral hygiene of pre-school and school aged children (16). Elementary schoolchildren are often insufficiently educated about the importance of oral hygiene, 
although they consider it as a key issue for self-confidence (17, 18). Most likely Croatian elementary schoolchildren have the same problem as well. According to WHO guidelines, prior to planning of any specific interventions aiming at achieving better oral health, the existing resources should be estimated: funding, staff education level, equipment and instruments availability, and existing infrastructure (19).

Croatia is the newest member of the European Union. Geopolitically, Croatia is a central European and Mediterranean state, with a surface area of $56.542 \mathrm{~km}^{2}$ and 4,284,889 inhabitants. For administrative purposes, the difference between rural and urban areas in the Republic of Croatia is based on territorial division, where smaller administrative units (municipalities) are considered rural and cities are considered urban. Based on these criteria, there are 20 counties, the city of Zagreb with special status, 127 cities and 429 municipalities. No accurate oral health data exist for Croatia to cover the past 20 years, which would systematically include oral health information on elementary schoolchildren (20). Therefore, the main goal of this study was to describe the caries prevalence in children from rural and urban areas, geographically located from east to south of the Republic of Croatia, by using specific indices which show the distribution of caries on primary and permanent teeth (DMFT, deft, DMFS, defs, and SiC).

\section{MATERIALS AND METHODS}

This cross-sectional study was conducted between September 2015 and September 2016 and the data were collected through epidemiological examination.

The study was conducted in the eastern part of the Republic of Croatia, in the region called Slavonia: in Štitar and Babina Greda, municipalities classified as villages, i.e. rural population, and Županja, which is classified as a town, forming the Slavonia region urban population. Other participants were from the city of Zagreb, the Republic of Croatia's capital located in central Croatia, and from the city of Dubrovnik located in the south of Croatia, and these participants also constituted an urban population group. A total of 187 children in Štitar, 78 in Babina Greda, 601 in Županja, 295 in Zagreb, and 428 in Dubrovnik were examined. For analysis purpose children were divided into two groups by age: younger children (aged 6-10 years, 913 examined) and older children (aged 11-16 years, 676 examined). The study was approved by the Ethics Committee of the Faculty of Dental Medicine in Zagreb, Croatia. All participants and their parents/guardians were informed about the research course and procedures involved. Examiners answered all additional questions before beginning of the research and before the signing of informed consent. Collected data were encrypted and available only to the examiners, as a base for eventual participants' recall during the research.

The children were examined at the dental offices according to standardized WHO conditions, under controlled hygiene and appropriate professional illumination. The clinical approach in the research was the same for all children and assumed a visual-tactile examination of the oral cavity with dental probes, dental mirrors and air syringe. Prior to clinical examination and oral status evaluation, all subjects had their teeth cleaned to remove soft and hard dental plaques using rotating brushes and polishing pastes.
The examination was performed by a team of experienced dental practitioners (trained and calibrated for clinical measurements), and the oral status data was recorded on previously prepared forms according to the published WHO's 1997 guidelines. Each tooth (or surface) that showed signs of lesions in pits, fissures or smooth surfaces (cavities, undermined enamel, or softened hard dental tissues) during visual inspection and probing was marked as carious. Evaluation was performed based on the WHO criteria and information about each tooth was recorded using codes (21).

Several indices typical for assessing caries prevalence were used in this study. The DMFT (decayed, missing, filled tooth) index indicates dental caries experience in the permanent dentition of the observed individual. The index is expressed numerically and shows the sum of decayed (D), extracted i.e. missing (M) and filled teeth $(\mathrm{F})$. The deft index (decayed, extracted, filled tooth) is an identical index assessing the state of primary dentition. The DMFS index (decayed, missing, filled surfaces) describes in more detail the presence of caries in permanent teeth as it relates to the number of dental surfaces that are carious, missing due to extraction or contain fillings. This index is established by adding the values for all examined tooth surfaces. For primary dentition, the same index is defined as defs. The SiC index (Significant Caries Index) emphasizes individuals with the highest DMFT index in a certain population. It describes the average DMFT value of $1 / 3$ of population with the largest DMFT scores.

A chi-square and Kolmogorov-Smirnov test were used to analyse data. A chi-square test was used to examine the correlations in dental caries prevalence in relation to sex, age and environment (Slavonia, Zagreb and Dubrovnik, and urban/rural areas). Kolmogorov-Smirnov test was used to test the normality of data distribution. That test showed that the original and transformed (logarithmic) DMFT and DMFS values were not normally distributed. Their standard deviations were the same or higher than the mean, thus using the mean and standard deviations as descriptive indicators was unjustified. The high variability in DMFT and DMFS was further visible from their quartile deviation coefficients. However, for the purpose of comparing our caries index results with similar studies, the means and standard deviations were also calculated. Microsoft Office Excel 2010 for Windows (Microsoft Corporation, Redmond, WA, USA) was used to input oral health status data and create charts. Data were analysed using SPSS 17.0 for Windows (SPSS Inc., Chicago, IL, USA). The statistical significance level was set at $\alpha=0.05$ ( $95 \%$ confidence interval). The inter-examiner reliability of kappa value was 0.957 based on the examination of 20 children of different ages before the study started.

\section{RESULTS}

A total of 1,589 children, 265 from rural and 1,324 from urban areas, 809 boys and 780 girls, were examined. There were 913 children from younger children group and 676 from older children group, with an average age of $11.0 \pm 2.5$ years. A total of 9,633 primary and 31,323 permanent teeth were examined.

The mean DMFT in all children was 3.03. For urban vs. rural areas, the mean DMFT was 2.84 and 3.95, respectively, and the difference was statistically significant $(\mathrm{p}<0.001)$. For younger children the mean DMFT was 1.8 (1.69 in urban and 2.23 in rural 
areas) and for older children the mean DMFT was 4.7 (4.56 in urban and 5.37 in rural areas). The difference between younger and older children was statistically significant $(\mathrm{p}<0.001)$. Rural children had significantly higher median DMFT $(p<0.001)$ and DMFS $(p<0.001)$ than children from urban areas (Table 2). The mean DMFT index differed significantly between Slavonia at 3.9, Zagreb at 2.5 and Dubrovnik at $1.7(\mathrm{p}<0.001)$. The DMFS index differed significantly between Slavonia, Zagreb and Dubrovnik, age, and area $(\mathrm{p}<0.001)$. The mean DMFS in all children was 4.8; for urban vs. rural areas, mean DMFS was 4.3 and 7.4, respectively $(p<0.001)$. The mean DMFS values were 2.6 for all younger children and 7.8 for all older children. The median DMFS values were 2 for all younger children and 6 for all older children. No significant difference was found in DMFT and DMFS between boys and girls $(\mathrm{p}=0.571$ and $\mathrm{p}=0.671)($ Table 1$)$.

The DMFT and DMFS indices increased with the children's age (Fig. 1). 12-year-olds had the mean DMFT 3.40, mean DMFS 5.33, the median DMFT was 3 and median DMFS was 4.

The Mann-Whitney U test showed that older children had also significantly higher median DMFT $(\mathrm{p}<0.001)$ and median DMFS $(p<0.001)$ than younger children. Children from urban areas had statistically significant higher number of healthy permanent teeth (33\%) compared to rural children (29.8\%). Children from different regions differed significantly in their number of completely healthy teeth $(\mathrm{p}<0.001)$. Most healthy permanent teeth were found in children from the Dubrovnik region $(76.2 \%)$, and the least healthy were in children from the Slavonia region $(32.2 \%)$.

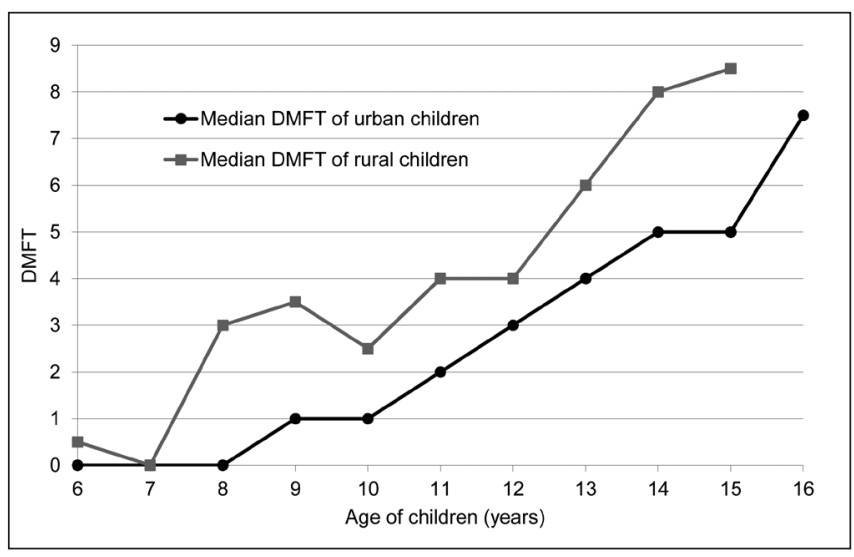

Fig. 1. Median DMFT of urban and rural children in Croatia by age.

Permanent teeth extractions (component M from DMFT) were rare. Of 1,589 children, only $40(2.5 \%)$ lacked one permanent tooth $(2.0 \%$ of urban children and $5.3 \%$ of rural children), and $33(2 \%)$ children were missing 2,3 or 4 permanent teeth $(2.2 \%$ of urban children and $1.5 \%$ of rural children). Of the examined children, $51.7 \%$ had at least one filling, with an average of 1.5 filled teeth per child. Of these, $52 \%$ were from urban areas, and $49 \%$ were from rural areas. Half of the examined children $(50.0 \%$ ) had caries (D component in DMFT), with $46 \%$ of these being from urban and $70.2 \%$ from rural areas. Of these, $18.1 \%$

Table 1. Means (standard deviations) of decayed, missing and filled permanent teeth (DMFT) and primary teeth (deft); decayed, missing and filled surfaces of permanent teeth (DMFS) and primary teeth (defs); significant caries index (SiC) by sex, age and region in Croatian schoolchildren $(N=1,589)$

\begin{tabular}{|c|c|c|c|c|c|c|c|c|}
\hline & \multicolumn{4}{|c|}{ Permanent teeth } & \multicolumn{4}{|c|}{ Primary teeth } \\
\hline & $\mathrm{n}$ & DMFT & DMFS & $\mathrm{SiC}$ & $\mathrm{n}$ & deft & defs & $\mathrm{SiC}$ \\
\hline \multicolumn{9}{|l|}{ Sex } \\
\hline Male & 809 & $3.0(3.3)$ & $5.0(6.9)$ & 4 & 499 & $4.7(3.4)$ & $8.2(11.2)$ & 10 \\
\hline Female & 780 & $3.1(3.2)$ & $4.7(6.4)$ & 4 & 464 & $4.4(3.2)$ & $7.5(10.2)$ & 8 \\
\hline Total & 1,589 & $3.0(3.29$ & $4.8(6.6)$ & 4 & 963 & $4.6(3.3)$ & $7.8(10.7)$ & 9 \\
\hline \multicolumn{9}{|l|}{ Age (years) } \\
\hline 12 & 202 & $3.4(2.9)$ & $6.1(7.6)$ & 4 & 81 & $2.0(2.0)$ & $4.6(6.3)$ & 3 \\
\hline $6-10$ & 913 & $1.8\left(2.0^{*}\right)$ & $2.6\left(3,5^{\star *}\right)$ & 2 & 847 & $4.9(3.3)$ & $12.6(11.5)$ & 17 \\
\hline $11-16$ & 676 & $4.7\left(3.8^{\star}\right)$ & $7.8\left(8.4^{* *}\right)$ & 6 & 116 & $1.8(1.9)$ & $1.1(3.6)$ & 0 \\
\hline Total & 1,589 & $3.0(3.2)$ & $4.8(6.6)$ & 4 & 963 & $4.6(3.3)$ & $7.8(10.7)$ & 9 \\
\hline \multicolumn{9}{|l|}{ Area } \\
\hline Urban & 1,324 & $2.8\left(3.1^{* \star *}\right)$ & $4.3\left(5.8^{*}\right)$ & 4 & 813 & $4.4(3.3)$ & $7.6(10.3)$ & 8 \\
\hline Rural & 265 & $4.0\left(3.5^{\star \star \star}\right)$ & $7.4\left(9.3^{*}\right)$ & 4 & 150 & $5.3(3.4)$ & $8.8(12.0)$ & 10 \\
\hline Total & 1,589 & $3.0(3.2)$ & $4.8(6.6)$ & 4 & 963 & $4.6(3.3)$ & $7.8(10.7)$ & 9 \\
\hline \multicolumn{9}{|l|}{ Region } \\
\hline Slavonia & 866 & $3.9\left(3.4^{\star \star *}\right)$ & $6.4\left(7.7^{\star \star}\right)$ & 4 & 473 & $4.8(3.3)$ & $7.8(11.3)$ & 8 \\
\hline Zagreb & 295 & $2.5\left(3^{* \star \star}\right)$ & $4.2\left(5.6^{* \star}\right)$ & 3 & 210 & $4.8(3.2)$ & $12.5(13.1)$ & 16 \\
\hline Dubrovnik & 428 & $1.7\left(2.3^{* * \star}\right)$ & $2.2\left(3.3^{* *}\right)$ & 2 & 280 & $3.9(3.3)$ & $7.8(8.3)$ & 9 \\
\hline Total & 1,589 & $3(3.2)$ & $4.8(6.6)$ & 4 & 963 & $4.6(3.3)$ & $7.8(10.7)$ & 9 \\
\hline
\end{tabular}

Statistical significance: ${ }^{*} p<0.05,{ }^{* *} p<0.01,{ }^{* * *} p<0.001$

Out of a total of 1,589 children, 963 had one or more primary teeth. 
Table 2. Median and coefficient quartile deviation of decayed, missing and filled teeth (DMFT), decayed, missing and filled surfaces (DMFS), significant caries index (SiC), decayed, extracted and filled primary teeth (deft), decayed, extracted and filled primary surfaces (defs) by sex, age and region in Croatian schoolchildren $(N=1,589)$

\begin{tabular}{|c|c|c|c|c|c|c|c|c|c|c|}
\hline & $n(\%)$ & SiC & $\begin{array}{l}\text { DMFT } \\
\text { median }\end{array}$ & $\begin{array}{c}\text { DMFT } \\
\text { coefficient } \\
\text { of quartile } \\
\text { deviation }\end{array}$ & $\begin{array}{l}\text { DMFS } \\
\text { median }\end{array}$ & $\begin{array}{l}\text { DMFS } \\
\text { coefficient } \\
\text { of quartile } \\
\text { deviation }\end{array}$ & $\begin{array}{c}\text { DMFT/ } \\
\text { DMFS x } \\
100\end{array}$ & $\begin{array}{c}\text { deft } \\
\text { median }\end{array}$ & $\begin{array}{c}\text { defs } \\
\text { median }\end{array}$ & $\mathrm{SiC}$ \\
\hline \multicolumn{11}{|l|}{ Sex } \\
\hline Male & $809(50.9)$ & 4 & 2 & 1.00 & 3 & 1.00 & 67 & 1 & 2 & 4 \\
\hline Female & $780(49.1)$ & 4 & 2 & 1.00 & 3 & 1.00 & 67 & 1 & 2 & 4 \\
\hline Total & $1,589(100)$ & 4 & 2 & 1.00 & 3 & 1.00 & 67 & 1 & 2 & 4 \\
\hline \multicolumn{11}{|l|}{ Age (years) } \\
\hline 12 & $202(12.7)$ & 4 & 3 & 0.60 & 4 & 0.56 & 75 & 2 & 2 & 3 \\
\hline $6-10$ & $913(57.5)$ & 3 & $1^{*}$ & 1.00 & $2^{* *}$ & 1.00 & 50 & 4 & 9 & 6 \\
\hline $11-16$ & $67642.5)$ & 6 & $4^{*}$ & 0.56 & $6^{* *}$ & 0.67 & 67 & 0 & 0 & 0 \\
\hline Total & $1,589(100)$ & 4 & 2 & 1.00 & 3 & 1.00 & 67 & 1 & 2 & 4 \\
\hline \multicolumn{11}{|l|}{ Area } \\
\hline Urban & $1,324(83.3)$ & 4 & $2^{* *}$ & 1.00 & $3^{*}$ & 1.00 & 67 & 1 & 2 & 4 \\
\hline Rural & 265 (16.7) & 5 & $4^{* *}$ & 0.71 & $5^{*}$ & 0.64 & 80 & 1 & 2 & 4 \\
\hline Total & $1,589(100)$ & 4 & 2 & 1.00 & 3 & 1.00 & 67 & 1 & 2 & 4 \\
\hline \multicolumn{11}{|l|}{ Region } \\
\hline Slavonia & $866(54.5)$ & 4 & $3^{*}$ & 0.67 & $4^{* * *}$ & 0.60 & 75 & 1 & 1 & 3 \\
\hline Zagreb & $295(18.6)$ & 4 & $1^{*}$ & 1.00 & $2^{* * *}$ & 1.00 & 50 & 3 & 9 & 5 \\
\hline Dubrovnik & $428(26.9)$ & 2 & $1^{*}$ & 1.00 & $1^{* * *}$ & 1.00 & 100 & 1 & 5 & 3 \\
\hline Total & $1,589(100)$ & 4 & 2 & 1.00 & 3 & 1.00 & 67 & 1 & 2 & 4 \\
\hline
\end{tabular}

Statistical significance: ${ }^{*} p<0.05,{ }^{* *} p<0.01,{ }^{* * *} p<0.001$

The last three columns provide information on the primary teeth of the children.

Table 3. Distribution of sound, decayed, filled and missing teeth by sex, age and region $(N=1,589)$

\begin{tabular}{|l|c|c|c|c|}
\hline Criteria & Sound teeth $\mathrm{n}(\%)$ & Decayed teeth $\mathrm{n}(\%)$ & Filled teeth $\mathrm{n}(\%)$ & Missing teeth $\mathrm{n}(\%)$ \\
\hline Total $\mathrm{n}(\%)$ & $794(50.0)$ & $795(50.0)$ & $822(51.7)$ & $73(4.6)$ \\
\hline Male & $379(47.0)$ & $430(54.0)$ & $393(47.8)$ & $31(42.5)$ \\
\hline Female & $415(53.0)$ & $365(46.0)$ & $429(52.2)$ & $42(57.5)$ \\
\hline 12 years & $90(11.3)$ & $112(14.1)$ & $67(8.2)$ & $6(8.2)$ \\
\hline $6-10$ years & $536(67.5)^{*}$ & $377(47.4)^{* *}$ & $336(40.9)^{*}$ & $13(17.8)$ \\
\hline $11-16$ years & $258(32.5)^{*}$ & $418(52.6)^{* *}$ & $486(59.1)^{*}$ & $60(82.2)$ \\
\hline Urban & $715(90.0)^{* *}$ & $609(76.6)^{*}$ & $693(84.3)$ & $55(75.3)^{*}$ \\
\hline Rural & $79(10.0)^{* *}$ & $186(23.4)^{*}$ & $129(15.7)$ & $18(24.7)^{*}$ \\
\hline Slavonia & $279(35.1)^{* * *}$ & $587(73.9)^{* *}$ & $480(58.4)^{* *}$ & $57(78.1)$ \\
\hline Zagreb & $189(23.8)^{* * *}$ & $106(13.3)^{* *}$ & $156(19.0)^{* *}$ & $10(13.7)$ \\
\hline Dubrovnik & $326(41.1)^{* *}$ & $102(12.8)^{* *}$ & $186(22.6)^{* *}$ & $6(8.2)$ \\
\hline
\end{tabular}

Statistical significance: ${ }^{*} p<0.05,{ }^{* *} p<0.01,{ }^{* * *} p<0.001$

children had one carious tooth (18.1\% from urban and $18.5 \%$ from rural areas), $10.3 \%$ had two carious teeth $(10.2 \%$ urban and $10.9 \%$ rural $), 7.4 \%$ had three carious teeth $(5.7 \%$ urban and $16.2 \%$ rural), and $14.2 \%$ of children had four or more carious teeth (12.1\% urban and $24.2 \%$ rural). The average number of carious teeth (D) increased with age. The urban average was $2.70 \%$ and the rural average was $3.34 \%$. Distribution of caries indices by sex, age and region are shown in Table 3.
Regarding primary teeth, $20.7 \%$ of children were caries-free (22.6\% urban children and $10.0 \%$ rural), $14.8 \%$ had one carious tooth (15.3\% urban and $12.7 \%$ rural), and $13.8 \%$ had two carious teeth (14.4\% urban and $10.7 \%$ rural). In primary teeth, $3.9 \%$ of children had one extracted primary tooth $(4.2 \%$ urban and $2.7 \%$ rural). As much as $75.6 \%$ of children had no dental fillings in their primary teeth $(73.9 \%$ urban and $85.0 \%$ rural $), 12.1 \%$ had only one filled primary tooth (12.7\% urban and $9.3 \%$ rural), $5.7 \%$ 
had 2 fillings in their primary teeth $(6.0 \%$ urban and $4.0 \%$ rural), and $6.5 \%$ had three or more dental fillings in their primary teeth (7.4\% urban and $1.7 \%$ rural). The mean deft in all children was 4.6, in urban areas it was 4.4, and in rural areas 5.3. There was a statistically significant difference between the defs indices among children's age groups and among different regions $(p<0.001)$. The median $\mathrm{SiC}$ index among children between 6 and 16 years of age was 4 , for urban areas 4 , and for rural areas 5 . The median SiC index for the younger children was 3 ( 2 in urban and 4 in rural areas); and for the older children 6 (6 in urban and 8 in rural areas).

\section{DISCUSSION}

In our research, half of the examined children (50\%) had caries (D component in DMFT), with $46 \%$ of these being from urban and $70.2 \%$ from rural areas. Oral health, quality of life and public health are interrelated. Oral health is considered an important part of the patient's general health. Poor oral health disturbs the quality of life and increases public health costs. Improving oral health, and thus the quality of life, is the main goal of today's dental care (22). Numerous epidemiological studies conducted on children population point to major differences in the caries prevalence among individual countries. The results of these scientific studies indicate that the silent caries epidemic has almost been stopped in recent years, in the countries of Western and Northern Europe and the United States $(8,12,23-28)$. Currently, the DMFT indices for 12-year-olds are as follows: 1 in France and Germany, 1.3 in Spain, less than 1.5 in the UK, 1.5 in Portugal (Lisbon), less than 2 in Sardinia (Italy) $(13,28-34)$.

Implementing systematic preventive public health programmes, massive and continuous fluoride use, improved oral hygiene, changed diet and living conditions, are the most common reasons thanks to which oral health have been improved. However, in Eastern and Central Europe, caries continues to pose a serious health and social problem $(8,12,23-28)$. In the epidemiological studies of Croatia's neighbouring countries, the following DMFT indices for 12-year-olds were found: 4.2 in Bosnia and Herzegovina, 3.7 in Albania, 3.5 in Macedonia, 3.2 in Poland, and 3.1 in Bulgaria (14). The mean DMFT for 12-year-olds in our study was 3.4, which indicates that Croatian children have DMFT index that is similar to that in Eastern and Central European countries. In a 2003 study on oral health in children from Central and Eastern Europe, economic and political changes during privatization and decentralization processes were reported as factors that negatively impacted oral health as they abolished preventive health programmes and examinations (12), so it was probably the same reason responsible for similar oral health situation in Croatia. Based on the available literature, the first epidemiological data related to caries in children in the Republic of Croatia were recorded in 1968. The DMFT index in 12-year-old children at that time was as high as 7. After that, DMFT was measured in 1973, 1980, 1985 and 1991, and through this period, the DMFT gradually decreased to $6.5,6.2,5.9$ and 2.6, respectively. In 1991, thanks to preventive programmes that were systematically applied throughout the country, the DMFT index in Croatia dropped to 2.6. Unfortunately, parallel with the war and transition process, oral health worsened again in the following years. The negative trend unduly continued through the post-war period to the present. The DMFT measured in 1999 was 3.5 (35). A 2003 study on caries in children found high deft/ DMFT and defs/DMFS indices in subjects from Petrinja and Topusko in the age groups of 3-6 and 11-14 years. The DMFT index was 6.67, deft was 7.7, and the $\mathrm{SiC}$ value was 10.89 (36). Epidemiological research on oral health in Central Dalmatia conducted in 2003 on a sample of 6-, 12- and 15-year-olds and adults aged 35-44 and 65-74 years showed a total DMFT index of 9.53. In 12-year-old population the DMFT was 3.85 (37). In 2007 , in a sample of children aged 4-5 and 10-12 years, the defs and DMFS values were very high, they ranged from 7.67 to 12.89 (18). Data collected from 2008 to 2009 among 6-year-old children showed the deft index value of 4.68 and a significant proportion of children with caries $(74.5 \%)(23)$. The results of our research show that the deft index is 4.80 ; in the urban areas 4.58 and in the rural ones 5.29. In a study on caries prevalence among schoolchildren in Zagreb in the period from 2009 to 2010 , the median DMFT and DMFS indices for all children were 3 and 4 , respectively. The mean DMFT and DMFS values were 4.1 and 5.6, respectively. The median indices for DMFT and DMFS for 12-year-old children were 4 and 5, respectively. DMFT and DMFS differed significantly between age groups (7-10 years and 11-14 years) as was the case in our research too. The authors recorded the highest mean deft index (5.5) in eight-year-olds, while our results showed the highest deft index at slightly younger age, in six-year-olds (24). Comparing the results from previous report and data from our study, data for primary teeth $\mathrm{dmft}$ and $\mathrm{dmfs}$ in the city of Zagreb changed from 4.1 and 5.6 in 2009-2010 to 2.5 and 4.2 in 2016, respectively. Furthermore, the median DMFT and DMFS values also improved from 3 and 4 in 2009-2010 to 1 and 2 in 2016, respectively. However, it must be stressed that there was a big difference in the total number of examined children, our study included 295 children from Zagreb, in contrast to 1,189 children from Zagreb in the 2009-2010 study (24). An oral examination of six-year-old children in the city of Rijeka showed the deft index of 3.68 and $22 \%$ of caries-free children (38). Our research shows a greater incidence of caries, the measured deft index of a 6-year-old is 7.72 (in urban areas it amounts to 6.82 and in rural ones to 9.63). The DMFT index in 6-year-olds recorded by the Central Health Information System of the Republic of Croatia (Croatian acronym CEZIH) from 2013 to 2015 was 4.14. According to the CEZIH data for the same period, the DMFT index for 12-year-olds was 4.18 (39). Our results showed that 12-year-olds had the mean DMFT index 3.4 (3.24 in urban children and 4.11 in rural children) and this indicates the slight improvement in oral health. However, the Croatian population did not reach the planned WHO goal for the year 2000, when the DMFT index for 12-year-olds was supposed to be below 3, nor the goal for 2010 when it was supposed to be below $1(40,41)$.

A 2003 study on oral health changes in 6- and 12-year-olds in Portugal assessed students' oral health and whether it was influenced by gender, urbanization, and existence of prevention programmes. The importance of implementing preventive programmes in schools has been established, as the caries prevalence rate has significantly been reduced over time. Retrospectively, in 1984, the deft in 6-year-olds was 5.2; and DMFT in 12-year-olds was 3.7. In 1999, the deft was 2.1, and DMFT was 1.5 (30).

According to our results, schoolchildren in the Republic of Croatia have the medium to high average DMFT index, based on 
WHO classification. Compared to Western and Northern European countries that belong mostly to the extremely low, low or rarely medium DMFT index groups based on WHO criteria, Croatia has a worrisome DMFT index level.

In March 2015, the Ministry of Health accepted the Strategic Plan for the Promotion and Protection of Oral Health 2015-2017, emanating from the National Strategy for Health Care Development for the 2012-2020 period. That Plan represents a key document which determines priorities in dental healthcare system. The National Caries Prevention Programme has been launched, consisting of many activities with the following goals: to increase the percentage of 6-year-olds with healthy teeth to $60 \%$, to lower the DMFT index of 12-year-olds to 3.5, to increase the use of fluoride-containing and remineralization products, and to improve the oral hygiene and nutritional habits of the entire population (42).

Caries and oral health data have been the focus of research interests in caries epidemiology worldwide for years. Sweden, Norway and Denmark are examples of countries that began collecting national caries data through public dental health care and have developed, and are continuing to develop, valuable systems to improve data quality and establish quality indicators of dental health care (43). To achieve the expected results, much work remains for Croatia in further developing a quality oral health monitoring and protection system, based on cooperation of many participants in that process including the Ministry of Health, the Croatian Institute of Public Health, the Croatian Institute for Health Insurance, dental medicine schools and dental health care providers.

\section{CONCLUSION}

Our results showed a medium caries prevalence among schoolchildren in Croatia, indicating a need for an extensive caries prevention programme. Oral health indices differ between children in urban and rural population. Children from both areas have the moderate to high DMFT index based on WHO classification, and epidemiological research is needed to cover all regions of Croatia and set the proper goals regarding necessary caries-preventive programmes and appropriate curative care. To reach these goals, a good preventive strategy is needed as well as systematic education of parents, children and dental practitioners on the importance of oral health preservation.

\section{Conflict of Interests}

None declared

\section{REFERENCES}

1. Petersen PE.The world oral health report 2003: continuous improvement of oral health in the 21 st century - the approach of the WHO Global Oral Health Programme. Geneva: WHO; 2003.

2. Hicks MJ, Flaitz CM. Epidemiology of dental caries in the pediatric and adolescent population: a review of past and current trends. J Clin Pediatr Dent. 1993;18(1):43-9.

3. Harris R, Nicoll AD, Adair PM, Pine CM. Risk factors for dental caries in young children: a systematic review of the literature. Community Dent Health. 2004;21 Suppl 1):71-85.

4. Holbrook WP, de Soet JJ, de Graaff J. Prediction of dental caries in preschool children. Caries Res. 1993;27(5):424-30.
5. Angelillo IF, Anfosso R, Nobile CGA, Pavia M. Prevalence of dental caries in school children in Italy. Eur J Epidemiol. 1998;14(4):351-7.

6. Namal N, Vehit HE, Can G. Risk factors for dental caries in Turkish preschool children. J Indian Soc Pedod Prev Dent. 2005;23(3):115-8.

7. Tamaki Y, Nomura Y, Katsumura S, Okada A, Yamada H, Tsuge S, et al. Construction of dental caries prediction model by data mining. J Oral Sci. 2009;51(1):61-8.

8. Gibson S, Williams S. Dental caries in pre-school children: associations with social class, tooth-brushing habit and consumption of sugars and sugar-containing foods. Caries Res. 1999;33(2):101-13.

9. Klein H, Palmer CE, Knutson JW. Dental status and dental needs of elementary school children. Public Health Rep. 1938;53:751-5.

10. Bratthall D. Introducing the Significant Caries Index to get her with a proposal for a new global oral health goal for 12-years-old. Int Dent J. 2000;50(6):378-84.

11. Abhishek M. Comprehensive review of caries assessment systems developed over the last decade. RSBO. 2012;9(3):316-21.

12. Petersen, PE. Changing oral health profiles of children in Central and Eastern Europe-Challenges for the 21st century. IC Digest. 2003;2:12-3.

13. Marthaler, TM. Changes in dental caries 1953-2003. Caries Res. 2004; 38(3):173-81

14. Malmö University. Dental Caries [Internet]. Malmö: Malmö University [cited 2017 Aug 2]. Available from: http://www.mah.se/CAPP/CountryOral-Health-Profiles/EURO/Croatia/Oral-Diseases/Dental-Caries/.

15. Choo A, Delac DM, Messer LB. Oral hygiene measures and promotion: review and considerations. Aust Dent J. 2001;46(3):166-73.

16. Maes L, Vereecken C, Vanobbergen J, Honkala S. Tooth brushing and social characteristics of families in 32 countries. Int Dent J. 2006;56(3):159-67.

17. Kasila K, Poskiparta M, Kettunen T, Pietilä I. Oral health counseling in changing school children's oral hygiene habits: a qualitative study. Community Dent Oral Epidemiol. 2006;34(6):419-28.

18. Gill P, Stewart K, Chetcuti D, Chestnutt IG. Children's understanding of and motivations for tooth brushing: a qualitative study. Int J Dent Hyg. 2011;9(1):79-86

19. Hobdell M, Petersen PE, Clarkson J, Johnson N. Global goals for oral health 2020. Int Dent J. 2003;53(5):285-8.

20. Statistical yearbook [Internet]. Central Bureau of Statistics; 2006 [cited 2017 Aug 2]. Available at: https://www.dzs.hr/Hrv_Eng/ljetopis/2006/02Binder.pdf. (In Croatian.)

21. World Health Organization. Oral Health Surveys: basic methods. Geneva: WHO; 1997.

22. Petričević N, Čelebić A, Baučić Božić M, Rener-Sitar K. Oral health and quality of life: important factor in patient treatment. Medix. 2008;75:62-6. (In Croatian.)

23. Jurić H, Škrinjarić I, Bošnjak A. Effectiveness of different preventive procedures in the control of some caries risk factors. Acta Stomatol Croat. 2007;41(1):39-48. (In Croatian, English.)

24. Dukić W, Delija B, Lulić-Dukić O. Caries prevalence among school children in Zagreb, Croatia. Croat Med J. 2011;52(6):665-71.

25. Marthaler TM, O'Mullane DM, Vrbic V. The prevalence of dental caries in Europe 1990-1995. ORCA Saturday afternoon symposium 1995. Caries Res. 1996;30(4):237-55.

26. Beltran-Aguilar ED, Barker LK, Canto MT, Dye BA, Gooch BF, Griffin $\mathrm{SO}$, et al. Surveillance for dental caries, dental sealants, tooth retention, edentulism, and enamel fluorosis-United States, 1988-1994 and 19992002. MMWR Surveill Summ. 2005;54(3):1-43.

27. Clark DC, Berkowitz J. The influence of various fluoride exposures on the prevalence of esthetic problems resulting from dental fluorosis. J Public Health Dent. 1997;57(3):144-9.

28. Enjary C, Tubert-Jeannin S, Manevy R, Roger-Leroi V, Riordan PJ. Dental status and measures of deprivation in Clermont- Ferrand, France. Community Dent Oral Epidemiol. 2006;34:363-71.

29. Borutta A, Brauner K, Hufnagl S, Marton S, Mavrodisz K, Tarjan I. Oral Health in 8-9 years-old children in Saxony-Anhalt (Germany) and in two Hungarian cities (Budapest and Debrecen). Community Dental Health. 2006;23(1):26-30.

30. Almeida D, Petersen PE, Jesus S, Toscano A, Toscano A. Changing oral health status of 6- and 12-yeras old school children in Portugal. Community Dent Health. 2003;20(4):211-6.

31. Demertzi A, Topitsoglou V, Muronidis S. Caries prevalence of 11,5 year-olds between 1989 and 2001 in a province of North Eastern Greece. Community Dent Health. 2006;23(3):140-6.

32. Campus G, Sacco G, Cagetti MG, Abati S. Changing trend of caries from 1989 to 2004 among 12-years old Sardinian children. BMC Public Health. 2007; 7:28. doi: 10.1186/1471-2458-7-28. 
33. Smyth E, Caamano F, Fernandez-Riveiro P. Oral health knowledge, attitudes and practice in 12-year-old school children. Med Oral Patol Oral Cir Bucal. 2007;12(8):614-20.

34. Gatou T, Koletsi Kounari H, Mamai-Homata E. Dental caries prevalence and treatment needs of 5- to 12-years old children in relation to area-based income and immigrant background in Greece. Int Dent J. 2011;61(3):14451.

35. Rajić, Z, Radionov, D, Rajić-Meštrović, S. Trends in dental caries in 12-year old children in Croatia. Coll Antropol. 2000;24 Suppl 1:21-4.

36. Jurić H, Klarić T, Lulić-Dukić O. Caries incidence in children with regard to their oral hygiene habits and past caries experience. Acta Stomatol Croat. 2003;37:340-1. (In Croatian, English.)

37. Bego K, Njemirovskij V, Pelivan, I. Epidemiological research on oral health in Central Dalmatia: a pilot study. Acta Stomatol Croat. 2007;41(4):337-44. (In Croatian, English.)

38. Bakarcic N, Jokic Ivancic I, Perkovic S, Hrvatin H, Kresina Glibotic H, Kresina S, et al. Caries Incidence in Children of Primorsko Goranska County, Croatia. J Oral Health Dent Sci. 2018;1:101-4.

39. Ministry of Health. National programme for prevention and oral care [Internet]. Zagreb: Ministry of Health of the Republic of Croatia; 2015 [cited 2017 Aug 2]. Available from: https://zdravlje.gov.hr/UserDocsImages//Programi\%20i\%20projekti\%20-\%20Ostali\%20programi//
NACIONALNI $\% 20$ PROGRAM $\% 20 Z$ A $\% 20$ PREVENTIVU $\% 20 I \% 20$ ZA\%C5\%A0TITU\%20ORALNOG\%20ZDRAVLJA.Vdocx.docx. (In Croatian.)

40. World Health Organization. The World Oral Health Report, 2003. Continuous improvement of oral health in the 21 st century-the approach of the WHO Global Oral Health Program. Geneva: WHO; 2003.

41. Hobdell MH, Myburgh NG, Kelman M, Hausen H. Setting global goals for oral health for the year 2010. Int Dent J. 2000;50(5):245-9.

42. Strategic plan of promotion and oral care 2015-2017 [Internet]. Zagreb: Ministry of Health of the Republic of Croatia; 2015 [cited 2017 Nov 1]. Available from: https://zdravlje.gov.hr/UserDocsImages/dokumenti/Programi, $\% 20$ projekti $\% 20 \mathrm{i} \% 20$ strategije/Strate $\%$ C5\%A1ki_plan,_za $\% 20$ oralno\%20zdravlje\%202015.pdf. (In Croatian.)

43. Skeie MS, Klock KS. Scandinavian systems monitoring the oral health in children and adolescents; an evaluation of their quality and utility in the light of modern perspectives of caries management. BMC Oral Health. 2014;30:14:43. doi: 10.1186/1472-6831-14-43.

Received February 7, 2018 Accepted in revised form July 4, 2019 